\title{
Marktwirtschaft und soziale Gerechtigkeit
}

\author{
Gestaltungsfragen der Wirtschaftsordnung in einer demokratischen Gesellschaft \\ Hrsg. v. Viktor J. Vanberg
}

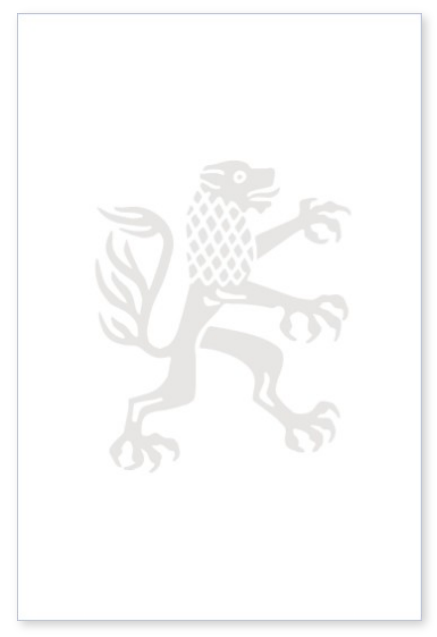

2012. VIII, 351 Seiten. UOrd 63

ISBN 978-3-16-152421-9

eBook PDF $69,00 €$

ISBN 978-3-16-150714-4

fadengeheftete Broschur 69,00€
In diesem Band wird das Verhältnis zwischen den Funktionsprinzipien und Wirkungseigenschaften marktwirtschaftlicher Ordnungen einerseits und dem Problem der »sozialen Gerechtigkeit« andererseits aus der Perspektive verschiedener Fachrichtungen wie der Philosophie, Sozial- und Wirtschaftsethik, Ökonomik, Soziologie, Politikwissenschaft, Rechtswissenschaft und Wirtschaftsdidaktik diskutiert. Dem liegt die Überzeugung zugrunde, dass die Klärung dieses Verhältnisses angesichts der in öffentlichen Foren deutlich werdenden Spannung zwischen den Herausforderungen marktwirtschaftlichen Wettbewerbs und verbreiteten Vorstellungen von »sozialer Gerechtigkeit« von besonderer gesellschaftspolitischer Bedeutung ist.

Inhaltsübersicht

Viktor J. Vanberg: Einführung: Marktwirtschaft und »soziale Gerechtigkeit«? Die Perspektive der Philosophie

Georg Lohmann: Marktwirtschaft und Menschenrechte - Martin Rechenauer: Soziale Marktwirtschaft und Gerechtigkeit. Eine Perspektive aus der Philosophie - Tilo Wesche: Gleichheit, Verdienst, Bedarf - Prinzipien der Gerechtigkeit Die Perspektive der Sozial- und Wirtschaftsethik

Gerhard Kruip: Marktwirtschaft und Gerechtigkeit. Die Perspektive der christlichen Sozialethik - André Habisch: Christliche Sozialethik und Marktwirtschaft - Jörg Althammer: Marktwirtschaft und Gerechtigkeitsfragen. Die Perspektive der Wirtschaftsethik - Michael Schramm: Normative Konflikte und flexible Gerechtigkeit - Moralökonomische Anmerkungen Die Perspektive der Ökonomik

Birger Priddat: Ökonomische Gerechtigkeit? Verträge als prozessuale fairness - Hermann Sautter: »Gerechtigkeit« aus ökonomischer Sicht - über die selbstgefällige Verdrängung eines Problems und neuere Ansätze zu seiner Thematisierung Hans Nutzinger: Gerechtigkeit in der Ökonomik

Die Perspektive der Soziologie

Michael Baurmann: Gerechtigkeitsüberzeugungen als kollektives Wissen. Marktwirtschaft und Gerechtigkeit aus Sicht der Soziologie - Stefan Liebig: Gerechtigkeit als Bedingung individueller Kooperationsbereitschaft in modernen Gesellschaften Erich Weede: Was kann die soziologische Gerechtigkeitsforschung zur Akzeptanz einer freien Marktwirtschaft sagen oder gar beitragen?

Die Perspektive der Politikwissenschaft

Uwe Wagschal: Gerechtigkeit und Marktwirtschaft in der OECD - ein Benchmark-Vergleich - Reinhard Zintl: Marktwirtschaft und Gerechtigkeit: Die Perspektive der Politikwissenschaft

Die Perspektive der Rechtswissenschaft

Christian Seiler: Marktwirtschaft und Gerechtigkeit. Gestaltungsfragen der Wirtschaftsordnung in einer demokratischen Gesellschaft - Ulrich Sartorius: Marktwirtschaft und Gerechtigkeit - Perspektive der Rechtswissenschaft Die Perspektive der Wirtschaftsdidaktik

Gerhard Minnameier: Marktmechanismus und Moral - berufsethische Orientierungen für Kaufleute in wirtschaftsdidaktischer Sicht - Hans-Jürgen Schlösser: Die Perspektive der Wirtschaftsdidaktik

Viktor J. Vanberg 1995-2009 Professor für Wirtschaftspolitik an der Universität Freiburg; 2001-10 Leiter des Walter Eucken Instituts Freiburg; seit 2010 Senior Research Fellow und Vorstand, Walter Eucken Institut.

https://orcid.org/0000-0002-2200-8260

Jetzt bestellen:

https://mohrsiebeck.com/buch/marktwirtschaft-und-soziale-gerechtigkeit-9783161524219?no_cache=1

order@mohrsiebeck.com

Telefon: $+49(0) 7071-923-17$

Telefax: $+49(0) 7071-51104$ 